\title{
DOHaD 2011 7th World Congress is programmed for progress
}

\author{
7th World Congress on Developmental Origins of \\ Health and Disease September 18-21, 2011 Portland, \\ Oregon, USA
}

The 7th World Congress on Developmental Origins of Health and Disease $(\mathrm{DOHaD})$ offers an unprecedented opportunity for basic and clinical scientists, physicians, epidemiologists, public health professionals and family-health-oriented caregivers to understand the paradigm shift that developmental programming is bringing to our understanding of human health and disease. In his famous treatise on the 'paradigm shifts' that underlie scientific revolutions, Kuhn ${ }^{1}$ envisioned scientific progress as a ladder and observed that scientists are notoriously slow to ascend from the safe and stable rung of the familiar to the perils of the untested next rung. We become inadvertently invested in the comfort of our own stories and protect them from perceived heretics. Finally, 20+ years after his seminal 1989 publication launching the field, our $\mathrm{DOHaD}$ Heretic-in-Chief - Professor David J. P. Barker - can rest assured that this rung on the scientific ladder has been accorded a consensus of solidity. Even so, we have yet to fully comprehend the degree to which the knowledge of developmental programming has and will continue to change our stories of biological truth, and with it our most basic concepts of disease. The 7th World Congress, led by Professor Barker as Honorary President, seeks to move us forward in redefining the human disease paradigm.

The organizers of DOHad 2011 have, first and foremost, designed the program to cross disciplinary boundaries, acknowledging the reality that a broad understanding of biological mechanisms at multiple levels is essential to serious translational progress. An unusually large number of plenary sessions (6) will ensure that all of the professionally diverse attendees will be exposed to expansions of basic concepts and to presentation of new data in new contexts, some highlighting aspects of programming that are often isolated to narrow specialty groups. The Opening Plenary addresses the broad global challenges of developmental programming and the worldwide impact of obesity. Other Plenary Sessions delve into territory that is critical to understanding developmental processes but not widely understood. For example, a full plenary on epigenetic mechanisms - so deeply relevant to programming - will be presented by exceptionally experienced researchers who can make these processes accessible to all while providing new information for those already fluent in molecular realms. Similarly, a DOHaD plenary session will for the first time address programming in the preterm infant, collating rapidly emerging information and raising key questions in this unique setting of enhanced susceptibility; another will consider the role of the still - mysterious placenta, the quintessential mediator of maternal-fetal nutrient transfer, as both a target and a mediator of programming forces. Showcasing these areas of progress emphasizes the remarkable breadth of the developmental programming field and bows to its mandate that we embrace early-life knowledge, no matter where along the lifecourse our own individual expertise might lie.

A second design feature of the DOHaD 2011 program is inclusion of emerging topics that - while still embryonic and in some cases yet-to-be recognized in $\mathrm{DOHaD}$ circles - are predicted to be critical to our full comprehension of developmental programming (e.g. innate immunity, maternal and fetal microbiomes, programmed malignancy). Finally, woven throughout the program are topics related to translational strategies: Can we prevent? Can we rescue? How can the science be directed to impact public policy and public health practice?

We are proud to report that 512 abstracts have been accepted after review by 3-4 experts from our $\mathrm{DOHaD} 2011$ Scientific Review Committee. We are exceptionally grateful to this eminent group for their critical contributions to the program. Approximately 90 abstracts have been selected for oral presentation. Due to the exceptionally high quality of the abstracts, as well as to the internationally recognized expertise of invited speakers, our Parallel Sessions have shaped up to be outstanding. Topics with particularly strong abstract responses included behavioral and neural programming, childhood obesity, postnatal growth and feeding patterns, environmental exposures, metabolic mechanisms, epigenetic and signaling pathways, and cohort studies. Some of the strongest and most novel abstracts were sufficiently hard to compartmentalize that we were pressed to create a "Hot Topics in Programming" Parallel Session - don't miss it! A detailed final program will be posted on the website www.dohad2011.org on or about 15 July 2011.

It was not possible to accommodate all of even the very top quality abstracts in oral sessions. As a result, the three poster sessions abound with new observations that challenge our 'stories' and advance our concepts. Poster Sessions include not only the topics covered by the parallel sessions, but also additional themes such as lactation, fertility/reproduction, micronutrients, preconception and prevention and rescue. Exhibit booths will showcase not only generous commercial supporters, but also the work and the methods of non-profit groups in Oregon that work toward and advocate for the health and well-being of mothers, babies and children. Our hope is to create dialogue across geographic boundaries about how we can eliminate obstacles and generate momentum for improving developmental nutrition at the local, hands-on level.

Four Satellite Meetings are also scheduled for before or after $\mathrm{DOHaD}$ 2011. These include: (i) $\mathrm{DOHaD}$ in Action: Why DOHaD Should Matter to Politicians, Health 
Administrators, and to the Public (John Challis); (ii) Behavior Change Skills for Use in Public Health Interventions in Women and their Children (Mary Barker and Caroline Fall); (iii) Innovations in Preterm Birth: Mechanisms and Consequences (John Newnham; Victoria Roberts; Terry Morgan); and (iv) Cardiac, Vascular, and Placental Contributions to Developmental Programming (Ron Magness; Lubo Zhang; Kent Thornburg). Please see www.DOHAD2011.org for location, program and registration details.

Finally, we have paid special attention to providing opportunities for socializing with your colleagues in uniquely Portland/Pacific Northwest settings. These include a welcome reception on sunday evening and a Mixer for junior investigators and junior faculty (only!) on Monday. Tuesday afternoon is reserved for Explore Portland Activities - choose a prearranged group outing (signup on registration site online) or arrange your own. A very special Congress Dinner awaits you on Tuesday evening at the Oregon Museum of Science and Industry - Northwest wines for tasting, a Northwest-style buffet dinner as you browse the entire museum; don't forget to bring your Inner Child to indulge in the awesome hands-on activity stations, take in the Planetarium Show, and dance to hip music (Please see www.dohad2011.org for details).

This is the firstever DOHaD World Congress to be held in the United States. We hope you can join your 500+ colleagues already signed up to help make this the mostmemorable ever!

Susan P. Bagby, M.D. Department of Medicine Oregon Health \& Science University

Portland, Oregon

\section{Reference}

1. Kuhn T. S. The Structure of Scientific Revolutions. 2nd edn, 1970, University of Chicago Press: Chicago, IL. 